This is an electronic reprint of the original article. This reprint may differ from the original in pagination and typographic detail.

Author(s): Haapala, Eero; Viitasalo, A.; Venäläinen, T.; Eloranta, A.-M.; Ågren, J.; Lindi, V.; Lakka, T. A.

Title: $\quad$ Plasma polyunsaturated fatty acids are directly associated with cognition in overweight children but not in normal weight children

Year: $\quad 2016$

Version:

Please cite the original version:

Haapala, E., Viitasalo, A., Venäläinen, T., Eloranta, A.-M., Ågren, J., Lindi, V., \& Lakka, T. A. (2016). Plasma polyunsaturated fatty acids are directly associated with cognition in overweight children but not in normal weight children. Acta Paediatrica, 105(12), 1502-1507. https://doi.org/10.1111/apa.13596

All material supplied via JYX is protected by copyright and other intellectual property rights, and duplication or sale of all or part of any of the repository collections is not permitted, except that material may be duplicated by you for your research use or educational purposes in electronic or print form. You must obtain permission for any other use. Electronic or print copies may not be offered, whether for sale or otherwise to anyone who is not an authorised user. 
Received Date : 20-Apr-2016

Revised Date : 08-Jul-2016

Accepted Date : 15-Sep-2016

Article type : Regular Article

\section{Plasma polyunsaturated fatty acids are directly associated with cognition in overweight children but not in normal weight children}

EA Haapala ${ }^{1,2^{*}}$, A Viitasalo $^{1^{\star}}$, T Venäläinen ${ }^{1}$, A-M Eloranta ${ }^{1}$, J Ågren ${ }^{1}$, V Lindi ${ }^{1}$, TA. Lakka ${ }^{1,3,4}$

*equal contribution

${ }^{1}$ School of Medicine, Institute of Biomedicine, University of Eastern Finland, Kuopio, Finland;

${ }^{2}$ Childhood Health \& Active Living Research Group, Department of Biology of Physical

Activity, University of Jyväskylä, Jyväskylä, Finland; ${ }^{3}$ Department of Clinical Physiology and

Nuclear Medicine, Kuopio University Hospital and University of Eastern Finland, Kuopio,

Finland; ${ }^{4}$ Kuopio Research Institute of Exercise Medicine, Kuopio, Finland

Short title: Polyunsaturated fatty acids and cognition

Address correspondence to: Eero A. Haapala, Ph.D., School of Medicine, Institute of Biomedicine, University of Eastern Finland, PO Box 1627, FI-70211 Kuopio, Finland, [eero.haapala@uef.fi], telephone: +358 40725 4025, fax: +35817 162131.

List of abbreviations:

AA: arachidonic acid

ALA: $\alpha$-linolenic acid

DHA: docosahexaenoic acid

EPA: eicosapentaenoic acid

PUFA: polyunsaturated fatty acids

This article has been accepted for publication and undergone full peer review but has not been through the copyediting, typesetting, pagination and proofreading process, which may lead to differences between this version and the Version of Record. Please cite this article as doi: 10.1111/apa.13596

This article is protected by copyright. All rights reserved. 


\section{ABSTRACT}

Aim: Polyunsaturated fatty acids are essential nutrients for the normal development of the brain. We investigated the associations between plasma polyunsaturated fatty acids and cognition in normal weight and overweight children.

Methods: The study recruited 386 normal weight children and 58 overweight children aged six to eight years and blood samples were drawn after a 12-hour fast. We assessed plasma polyunsaturated fatty acids using gas chromatography, cognition using Raven's Coloured Progressive Matrices, and overweight and obesity using the age-specific and sex-specific cut-offs from the International Obesity Task Force. The data were analysed by linear regression analyses adjusted for age and sex.

Results: Higher proportions of eicosapentaenoic acid in plasma triacylglycerols $(\beta=0.311$, $p=0.020, p=0.029$ for interaction) and docosahexaenoic acid in plasma triacylglycerols ( $\beta=0.281, p=0.038, p=0.049$ for interaction) were both associated with higher Raven's scores in overweight children but not in normal weight children. Higher eicosapentaenoic acid to arachidonic acid ratios in triacylglycerols $(\beta=0.317, p=0.019)$ and phospholipids $(\beta=0.273$, $\mathrm{p}=0.046$ ) were directly associated with the Raven's score in overweight children but not in normal weight children.

Conclusions: These findings suggest that increasing the consumption of fish and other sources of eicosapentaenoic acid and docosahexaenoic acid may improve cognition among overweight children.

Key words: cognition, fish consumption, overweight, plasma, polyunsaturated fatty acids

This article is protected by copyright. All rights reserved. 


\section{KEY NOTES}

- Polyunsaturated fatty acids are essential for normal brain development, but few studies have investigated their association with childhood cognition.

- Our study of 444 normal and overweight children aged 6-8 years showed that higher proportions of polyunsaturated fatty acids in plasma were related to better cognition in overweight, but not normal weight, children.

- The findings suggest that increasing the consumption of polyunsaturated fatty acids would help improve cognition among overweight children.

\section{INTRODUCTION}

Polyunsaturated fatty acids (PUFAs) are essential nutrients for normal development of the brain and cognition $(1,2)$ and should be obtained from diet because the body has a limited ability to synthetise them (2,3). A typical Western diet is low in sources of PUFAs, and less than half of the children in Western countries meet the recommended intake of PUFAs and particularly those of $n-3$ fatty acids docosahexaenoic acid (DHA) and eicosapentaenoic acid (EPA) $(4,5)$.

Some studies suggests that a higher dietary intake of PUFAs has been related to better short-term memory in children $(6,7)$. Furthermore, studies have suggested that a higher intake of n-3 PUFA supplements, especially DHA, may improve cognitive functions during the perinatal period and infancy but not in childhood or adulthood (7-10). Few studies have investigated the associations of the plasma biomarkers of PUFA status with cognition in children and these studies have provided inconsistent results $(7,11)$. Nevertheless, one study found that increased whole-blood DHA and EPA concentrations after a three month school meal intervention were related to greater improvements in reading performance in nine to 11-yearold children (12). Furthermore, paediatric overweight, which has emerged as an important global public health concern

This article is protected by copyright. All rights reserved. 
(13), has also been linked to impaired development of the brain and cognition (14).

There have not been any studies on the associations between plasma PUFAs and cognition in normal weight and overweight or obese children. We therefore investigated these associations in a population-based sample of children and examined whether being overweight or obese modified these associations.

\section{METHODS}

\section{Study population}

The present analyses were based on the baseline data from the Physical Activity and Nutrition in Children (PANIC) study, which is an on-going physical activity and diet intervention study in a population sample of primary school children from the city of Kuopio, Finland (4). A total of 736 children aged 6-8 years were invited to participate in the baseline examinations between 2007 and 2009 and $512(70 \%)$ participated. The participants did not differ from other children of the same age, whose data were obtained from school health examinations (data not shown), when it came to sex distribution, age or their body mass index standard deviation score (BMI-SDS). After excluding children with developmental disabilities, attention deficit hyperactivity disorder or incomplete data from the analyses, the final study sample comprised 444 children: 219 girls and 225 boys. The PANIC Study protocol was approved by the Research Ethics Committee of the Hospital District of Northern Savo, Finland, and the children and their parents gave their written informed consent.

This article is protected by copyright. All rights reserved. 


\section{Assessment of body size and composition}

The body fat percentage was measured by the Lunar Prodigy Advance dualenergy x-ray absorptiometry device (GE Medical Systems, Madison, Wisconsin, USA) (15). Body height and weight were measured and BMI-SDS was calculated using Finnish references (16). The prevalence of overweight was defined using the age-specific and sex-specific cut-offs from the International Obesity Task Force (17).

\section{Assessment of fatty acids}

Blood samples were drawn after 12-hour fasting. Plasma PUFAs were analysed as described earlier (18) and were expressed in mol\%. In short, the plasma samples were extracted with chloroform-methanol (2:1) and the lipid fractions were separated by solid phase extraction with an aminopropyl column. The fatty acids in plasma cholesteryl esters, phospholipids and triacylglycerols were transmethylated with $14 \%$ boron trifluoride in methanol and were analyzed by the 7890A gas chromatograph (Agilent Technologies Inc., Wilmington, Delaware, USA) equipped with a 25-m FFAP column. Cholesteryl nonadecanoate (Nu Chek Prep Inc., Elysian, Minnesota, USA), trinonadecanoin and phosphatidylcholine dinonadecanoyl (Larodan Fine Chemicals, Malmö, Sweden) served as internal standards. In the analyses, we used the proportions of $\alpha$-linolenic acid (ALA), EPA, DHA and docosapentaenoic acid (DPA) and the ratio of EPA or DHA to arachidonic acid (AA) (19).

This article is protected by copyright. All rights reserved. 


\section{Assessment of cognition}

We used Raven's Coloured Progressive Matrices (Raven's CPM) to assess nonverbal reasoning (20). One trained researcher administered these assessments. Raven's CPM includes 36 large figures with a part missing. The children were asked to select the correct part that completed the figure from six alternatives presented beneath the large figure. Raven's CPM requires the ability to find similarities, differences, and discrete patterns, does not depend on acquired knowledge or language skills (20), and has been suggested to represent all-core components of executive functions (21). The Raven's CPM score was the number of correct answers, ranging from zero to 36 .

\section{Other assessments}

Total physical activity and total sedentary behaviour were assessed using the PANIC Physical Activity Questionnaire, which was filled out by the parents (22). The parents were also asked to report their highest completed or on-going educational levels - vocational school or less, polytechnic, university - and the annual house-hold income in Euros, from the ranges $\leq 30,000,30,001-60,000$, and $\geq 60,001$. The level of the more educated parent was used in the analyses. We assessed food consumption and nutrient intake by food records administered by the parents on four predefined consecutive days. Of the food diaries, $99.5 \%$ included two weekdays and two weekend days and $0.5 \%$ included three weekdays and one weekend day. We assessed the number of meals per day based on data from the food records, classifying breakfast, lunch, and dinner as main meals and all eating and drinking between main meals as snacks. We categorised the children into those who had eaten all main meals daily and those who had skipped any of their main meals. The food records were analysed and we calculated total energy intake using the Micro Nutrica dietary analysis

This article is protected by copyright. All rights reserved. 
software, Version 2.5 (The Social Insurance Institution of Finland), that uses Finnish and international data on the nutrient composition of foods (23). Parents were asked to report any medically diagnosed Attention-deficit hyperactivity disorder or other developmental disorder. The research physician assessed pubertal status using the five-stage criteria described by Tanner (24). The boys were defined as having entered clinical puberty, if their testicular volume assessed by an orchidometer was stage two or more, which is more than $3 \mathrm{ml}$. The girls were defined as having entered puberty, if their breast development had started, which is also stage two or more. Genomic DNA was isolated from the blood mononuclear cells using the QIAamp DNA Blood kit (Qiagen, Hilden, Germany). Common fatty acid desaturase polymorphisms (rs174547 and rs174616) were extracted from the Human Core Exome Chip (Illumina, San Diego, California, USA). The genotypes were determined by using GenomeStudio (Illumina, San Diego, California, USA). Quality control was carried out using the free, open-source whole genome association analysis toolset PLINK Version 1.07.

\section{Statistical methods}

We performed all data analyses using SPSS Statistics software, Version 19.0 (IBM Corp., Armonk, New York, USA). The Student's t-test was used to investigate the differences in basic characteristics between normal weight and overweight or obese children. The associations of plasma PUFA proportions with the Raven's CPM score were analysed by linear regression adjusted for age and sex. Data were additionally adjusted for body fat percentage, clinical puberty, eating main meals, the dietary intakes of carbohydrates and sucrose, physical activity, sedentary behaviour, parental education, annual household income, and common fatty acid desaturase gene polymorphisms (rs174547 and rs174616)

This article is protected by copyright. All rights reserved. 
which were entered into the model one by one with age and sex. We used general linear models adjusted for age and sex to study whether overweight and obesity modified the relationships between plasma PUFAs in cholesteryl esters, phospholipids, and triacylglycerols and the Raven's CPM score. Because of small number of pubertal children in the present study sample, we also performed the analyses without children who had entered clinical puberty.

\section{RESULTS}

The characteristics of normal weight and overweight or obese children are presented in Table 1. Higher proportions of EPA ( $p=0.029$ for interaction) and DHA ( $p=0.049$ for interaction) in plasma triacylglycerols and a higher EPA to AA ratio in plasma triacylglycerols and phospholipids were associated with a higher Raven's CPM score in overweight or obese children but not in normal weight children (Table 2). Additional adjustment for annual household income slightly attenuated the associations of the proportions of $\mathrm{DHA}(\beta=0.233, p=0.086)$ and EPA $(\beta=0.261, p=0.055)$ in plasma triacylglycerols as well as EPA to AA ratio in plasma triacylglycerols $(\beta=0.284, p=0.037)$ and phospholipids $(\beta=0.223$, $\mathrm{p}=0.105$ ) with the Raven's CPM score in overweight or obese children. Other adjustments had no effects on these associations. The results remained virtually the same after excluding the children who had entered clinical puberty.

\section{DISCUSSION}

We found that higher proportions of DHA and EPA in plasma triacylglycerols and a higher EPA to AA ratio in plasma triacylglycerols and phospholipids were associated with a higher Raven's CPM score among overweight or obese

This article is protected by copyright. All rights reserved. 
children. However, none of the plasma PUFAs were related to the Raven's CPM score among normal weight children.

There are few studies on the associations between the proportions of blood or plasma PUFAs and cognition in school-aged children $(7,11)$. Montgomery et al (11) found no association between the proportion of DHA in blood and working memory but observed a direct relationship between the proportion of combined DHA and EPA in blood and working memory in children (11). Boucher et al (7) found no associations between the proportions of DHA, EPA, or other n-3 fatty acids in blood phospholipids and working memory in children. However, these studies did not take the possible modifying effect of adiposity into account. Our results suggest that the relationship between EPA, DHA, and the EPA to AA ratio and cognition was stronger in overweight or obese children than in normal weight children.

One explanation for the direct associations of plasma EPA, DHA and the EPA to AA ratio with cognition in the present study, may be that a higher dietary intake of EPA and DHA may reduce low-grade inflammation and improve brain structures and functions, which have been observed to be impaired in overweight children compared to normal weight children (2). Accordingly, some evidence has suggested inverse associations of whole blood PUFA concentration and the EPA to AA ratio with inflammatory markers in children and that body adiposity may modify these associations (25). Therefore, an adequate intake of EPA and DHA may be more important in the normal development of the brain and cognition among overweight and obese children than in normal weight children.

We found direct associations between EPA and DHA in plasma triacylglycerols, which have been suggested to reflect the fatty acid intake of the last few days, with the Raven's CPM score in overweight or obese children. However, we observed no associations between these fatty acids in plasma

This article is protected by copyright. All rights reserved. 
cholesteryl esters or phospholipids, which reflect the dietary fat composition of preceding months (26), with cognition in children. The blood sampling and the cognitive testing were not performed on the same day and that makes it difficult to conclude that eating foods high in EPA and DHA before the cognitive test had beneficial effects on cognitive performance in overweight children. Nevertheless, direct associations of the EPA to AA ratio in plasma triacylglycerols and phospholipids with cognition in overweight or obese children suggest that a higher intake of EPA and DHA over months and years could have positive effects on the brain (2), particularly in overweight and obese children.

Household income partly explained the associations between plasma EPA and DHA with the Raven's CPM score. Low household income and poverty have been inversely associated with brain development and cognitive functions in children $(27,28)$. We previously found that children from families with a lower household income were less likely to eat fish, which is the main source of EPA and DHA in Finland, than other children (4). Together with these observations, our current results suggest that poorer cognition in overweight or obese children from families with a lower household income may be partly modified by a lack of sources of EPA and DHA. However, further longitudinal studies are needed to explore the modifying effects of diet on the development of brain and cognition in children from a lower socioeconomic background.

The strengths of the present study included a relatively large population sample of children and the rigorous methods used to assess the plasma proportions of PUFAs. We also had an opportunity to control the data for a number of possible confounding factors in the analyses. The limitations of our study are the cross-sectional design which does not allow us to make conclusions about the causality of the relationships and the use of only one 
measure of cognition instead of more comprehensive cognitive testing. There was limited statistical power in the analyses due to the relatively small number of overweight or obese children.

\section{CONCLUSION}

Our results suggest that the proportions of EPA and DHA in plasma triacylglycerols and the EPA to AA ratio in plasma triacylglycerols and phospholipids were directly associated with cognition in overweight or obese children but not in normal weight children. These findings provide some evidence that increasing the consumption of fish and other sources of EPA and DHA may improve cognition, particularly among overweight or obese children.

\section{ACKNOWLEDGEMENTS}

We thank all the children and their families who volunteered to participate in the study.

\section{FUNDING}

The PANIC Study was financially supported by grants from the Jenny and Antti Wihuri Foundation, Päivikki and Sakari Sohlberg Foundation, Ministry of Social Affairs and Health of Finland, Ministry of Education and Culture of Finland, University of Eastern Finland, Finnish Innovation Fund Sitra, Social Insurance Institution of Finland, Finnish Cultural Foundation, Juho Vainio Foundation, Foundation for Pediatric Research, Paulo Foundation, Paavo Nurmi Foundation, Diabetes Research Foundation, Kuopio University Hospital (erityisvaltionosuus [EVO] funding number 5031343) and the Research Committee of the Kuopio University Hospital Catchment Area for the State Research Funding, City of Kuopio.

This article is protected by copyright. All rights reserved. 


\section{CONFLICTS OF INTEREST}

The authors have no conflicts of interest to declare

\section{REFERENCES}

1. Nyaradi A, Li J, Hickling S, Foster J, Oddy WH. The role of nutrition in children's neurocognitive development, from pregnancy through childhood. Front Hum Neurosci 2013;7:97.

2. Bazinet RP, Layé S. Polyunsaturated fatty acids and their metabolites in brain function and disease. Nat Rev Neurosci 2014;15:771-85.

3. Kirby A, Woodward A, Jackson S. Benefits of omega-3 supplementation for schoolchildren: review of the current evidence. Br Educ Res J 2010;36:699-732.

4. Eloranta AM, Lindi V, Schwab U, Kiiskinen S, Kalinkin M, Lakka HM, et al. Dietary factors and their associations with socioeconomic background in Finnish girls and boys 6-8 years of age: the PANIC Study. Eur J Clin Nutr 201;65:1211-8.

5. Schuchardt JP, Huss M, Stauss-Grabo M, Hahn A. Significance of long-chain polyunsaturated fatty acids (PUFAs) for the development and behaviour of children. Eur J Pediatr 2010;169:149-64.

6. Zhang J, Hebert J, Muldoon M. Dietary fat intake is associated with psychosocial and cognitive functioning of school-aged children in the United States. J Nutr 2005;135:1967-73.

7. Boucher O, Burden MJ, Muckle G, Saint-amour D, Ayotte P, Dewailly E, et al. Neurophysiologic and neurobehavioral evidence of beneficial effects of prenatal omega-3 fatty acid intake on memory function at school age. Am J Clin Nutr 2011;93:1025-37.

8. Innis SM. Dietary omega 3 fatty acids and the developing brain. Brain Res

This article is protected by copyright. All rights reserved. 
2008;1237:35-43.

9. Jiao J, Li Q, Chu J, Zeng W, Yang M, Zhu S. Effect of n-3 PUFA supplementation on cognitive function throughout the life span from infancy to old age: a systematic review and meta-analysis of randomized controlled trials. Am J Clin Nutr J Clin Nutr 2014;100:1422-36.

10. Khan NA, Raine LB, Drollette ES, Scudder MR, Kramer AF, Hillman CH. Dietary fiber is positively associated with cognitive control among prepubertal children. $J$ Nutr $2015 ; 145: 143-9$.

11. Montgomery P, Burton JR, Sewell RP, Spreckelsen TF, Richardson AJ. Low blood long chain Omega-3 fatty acids in UK children are associated with poor cognitive performance and behavior: A cross-sectional analysis from the DOLAB Study. PLoS One 2013;8:e66697.

12. Sørensen LB, Damsgaard CT, Dalskov S-M, Petersen RA, Egelund N, Dyssegaard $\mathrm{CB}$, et al. Diet-induced changes in iron and n-3 fatty acid status and associations with cognitive performance in 8-11-year-old Danish children: secondary analyses of the Optimal Well-Being, Development and Health for Danish Children through a Healthy New Nordic Diet. Br J Nutr 2015;114:1623-37.

13. Ng M, Fleming T, Robinson M, Thomson B, Graetz N, Margono C, et al. Global, regional, and national prevalence of overweight and obesity in children and adults during 1980-2013: a systematic analysis for the Global Burden of Disease Study 2013. Lancet $2014 ; 6736: 766-81$.

14. Yates KF, Sweat V, Yau PL, Turchiano MM, Convit A. Impact of metabolic syndrome on cognition and brain: a selected review of the literature. Arterioscler Thromb Vasc Biol 2012;32:2060-7.

15. Tompuri TT, Lakka TA, Hakulinen M, Lindi V, Laaksonen DE, Kilpeläinen TO, et al. Assessment of body composition by dual-energy X-ray absorptiometry, bioimpedance

This article is protected by copyright. All rights reserved. 
analysis and anthropometrics in children: the Physical Activity and Nutrition in Children study. Clin Physiol Funct Imaging 2015;35:21-33.

16. Saari A, Sankilampi U, Hannila M-L, Kiviniemi V, Kesseli K, Dunkel L. New Finnish growth references for children and adolescents aged 0 to 20 years: Length/height-forage, weight-for-length/height, and body mass index-for-age. Ann Med 2011;43(3):235-48.

17. Cole T, Bellizzi M, Flegal K, Dietz W. Establishing a standard definition for child overweight and obesity worldwide: international survey. Br Med J 2000;320:1240-3.

18. Venäläinen T, Schwab U, Ågren J, de Mello V, Lindi V, Eloranta A-M, et al. Crosssectional associations of food consumption with plasma fatty acid composition and estimated desaturase activities in Finnish children. Lipids 2014;49:467-79.

19. Yagi S, Hara T, Ueno R, Aihara K, Fukuda D, Takashima A, et al. Serum concentration of eicosapentaenoic acid is associated with cognitive function in patients with coronary artery disease. Nutr J 2014;13:112.

20. Raven J, Raven J, Court J. Coloured Progressive Matrices. Manual for Raven's Progressive Matrices and Vocabulary Scales. London: Oxford Psychologist Press Ltd.; 1998.

21. Diamond A. Executive functions. Annu Rev Psychol . 2013;64:135-68.

22. Väistö J, Eloranta A-M, Viitasalo A, Tompuri T, Lintu N, Karjalainen P, et al. Physical activity and sedentary behaviour in relation to cardiometabolic risk in children: crosssectional findings from the Physical Activity and Nutrition in Children (PANIC) Study. Int J Behav Nutr Phys Act 2014;11:55.

23. Eloranta A-M, Lindi V, Schwab U, Tompuri T, Kiiskinen S, Lakka H-M, et al. Dietary factors associated with overweight and body adiposity in Finnish children aged 6-8 years: the PANIC Study. Int J Obes 2012;36:950-5.

24. Tanner J. Growth at adolescence. Oxford: Blackwell; 1962.

This article is protected by copyright. All rights reserved. 
25. González-Gil EM, Santabárbara J, Siani A, Ahrens W, Sioen I, Eiben G, et al. Wholeblood fatty acids and inflammation in European children: the IDEFICS Study. Eur J Clin Nutr 2016; 70: 819-23.

26. Vessby B, Gustafsson I, Tengblad S, Boberg M, Andersson A. Desaturation and elongation of Fatty acids and insulin action. Ann N Y Acad Sci 2002; 967: 183-95.

27. Noble KG, Engelhardt LE, Brito NH, Mack LJ, Nail EJ, Angal J, et al. Socioeconomic disparities in neurocognitive development in the first two years of life. Dev Psychobiol $2015 ; 57: 535-51$.

28. Hair NL, Hanson JL, Wolfe BL, Pollak SD. Association of child poverty, brain development, and academic achievement. JAMA Pediatr 2015;169:822-9.

This article is protected by copyright. All rights reserved. 
Table 1 . The characteristics of 386 normal weight children and 58 overweight or obese children

\begin{tabular}{llll}
\hline & $\begin{array}{l}\text { Normal weight } \\
\text { children (n=386) }\end{array}$ & $\begin{array}{l}\text { Overweight } \\
\text { children (n=58) }\end{array}$ & \\
& & & -value \\
& $7.6(0.4)$ & $7.7(0.4)$ & 0.059 \\
\hline Age (years) & $128.3(5.4)$ & $131.9(5.2)$ & $<0.001$ \\
Body height (cm) & $25.6(3.4)$ & $35.3(4.3)$ & $<0.001$ \\
Body weight (kg) & $-0.45(0.86)$ & $1.59(0.44)$ & $<0.001$ \\
BMI-SDS & $17.6(5.9)$ & $34.3(5.5)$ & $<0.001$ \\
Body fat percentage (\%) & $24.2(5.1)$ & $23.0(5.3)$ & 0.109 \\
Raven Coloured Progressive Matrices score & $1.74(0.57)$ & $1.71(0.58)$ & 0.697 \\
18:3n-3 $\alpha$-linolenic acid in plasma TG (mol \%) & $0.66(0.24)$ & $0.62(0.21)$ & 0.207 \\
20:5n-3 EPA in plasma TG (mol \%) & $0.63(0.47)$ & $0.57(0.45)$ & 0.371 \\
22:5n-3 DPA in plasma TG (mol \%) & $1.46(0.77)$ & $1.45(0.71)$ & 0.962 \\
22:6n-3 DHA in plasma TG (mol \%) & $1.04(0.22)$ & $1.07(0.23)$ & 0.386 \\
18:3n-3 $\alpha$-linolenic acid in plasma CE (mol \%) & $1.25(0.55)$ & $1.32(0.43)$ & 0.357 \\
20:5n-3 EPA in plasma CE (mol \%) & $0.80(0.21)$ & $0.83(0.26)$ & 0.260 \\
22:6n-3 DHA in plasma CE (mol \%) & $0.40(0.11)$ & $0.40(0.14)$ & 0.708 \\
18:3n-3 $\alpha$-linolenic acid in plasma PL (mol \%) & $1.27(0.52)$ & $1.32(0.45)$ & 0.488 \\
20:5n-3 EPA in plasma PL (mol \%) & $1.28(0.20)$ & $1.29(0.19)$ & 0.849 \\
22:5n.3 DPA in plasma PL (mol \%) & $4.66(1.07)$ & $4.75(0.95)$ & 0.538 \\
22:6n-3 DHA in plasma PL (mol \%) & & & \\
\hline
\end{tabular}

Values are means (standard deviations) from the Students t-test. BMI-SDS = body mass index standard deviation score, based on Finnish reference values (Saari et.al.); $\mathrm{CE}=$ Cholesteryl esters; DHA= Docosahexaenoid acid; DPA= Docosapentaenoic acid; EPA=Eicosapentaenoic acid; PL= phospholipids; TG=triacylglycerols

This article is protected by copyright. All rights reserved. 
Table 2. The associations of polyunsaturated fatty acids in plasma triacylglycerols, cholesteryl esters, and phospholipids with Raven's Coloured

Progressive Matrices score in normal weight and overweight or obese children.

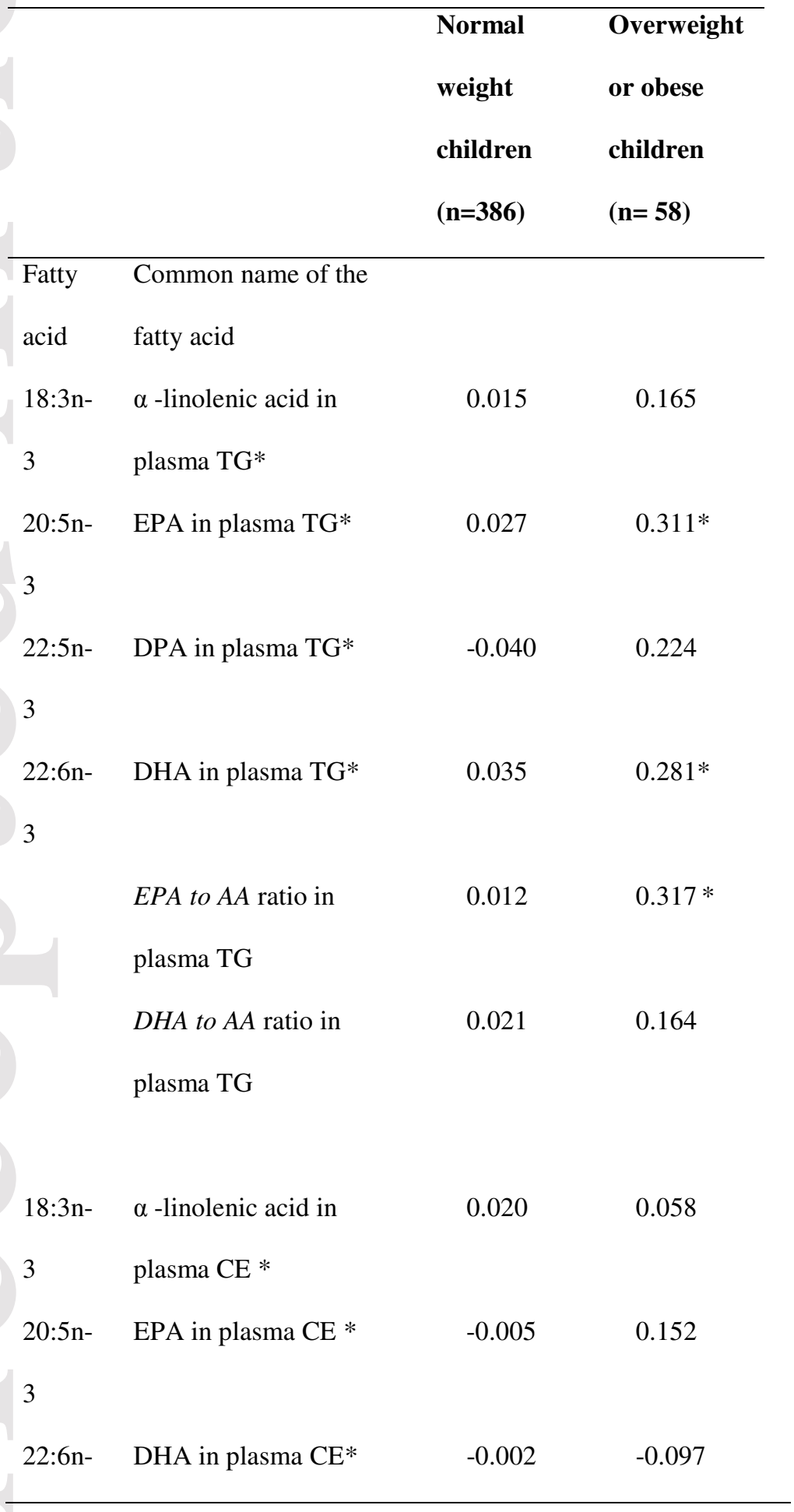

This article is protected by copyright. All rights reserved. 


$\begin{array}{lll}\text { EPA to } A A \text { in plasma CE } & -0.022 & 0.251 \\ \text { DHA to } A A \text { ratio in } & 0.004 & 0.023\end{array}$

plasma $\mathrm{CE}^{*}$

18:3n- $\quad \alpha$-linolenic acid in $\quad-0.038 \quad 0.039$

3 plasma PL

20:5n- EPA in plasma PL

$-0.009$

0.251

D

3

22:5n.3 DPA in plasma PL*

$0.009 \quad 0.074 \quad \mathrm{t}$

22:6n- DHA in plasma PL

0.045

0.091

a

3

EPA to $A A$ ratio in

plasma $P L^{*}$

DHA to $A A$ ratio in

plasma $P L *$

tandardized regression coefficients $(\beta)$ from linear regression models adjusted for age and sex.

*Logarithmic transformation was carried out, because of skewed distributions.

$\mathrm{CE}=$ Cholesteryl esters; $\mathrm{AA}=$ Arachinoid acid;

DHA= Docosahexaenoid acid DPA $=$

Docosapentaenoic acid; EPA=Eicosapentaenoic

acid;PL= phospholipids;

TG=triacylglycerols. $* P<0.05$.

This article is protected by copyright. All rights reserved. 